\title{
C-reactive protein is inversely and independently associated with maximal oxygen uptake in adolescents with obesity
}

http://dx.doi.org/10.11606/1807-5509202000030463

\author{
J oão Elias Dias NUNES*/** \\ Heitor Santos CUNHA *** \\ Renata Roland TEIXEIRA** \\ Foued S. ESPINDOLA ${ }^{* *}$ \\ Nádia Carla $\mathrm{CHEIK}^{* * * *}$
}

* Laboratory of the Physiology of Performance, Federal University of Uberlândia Uberlândia, MG, Brazil. ** Laboratory of the Biochemistry and Molecular Biology, Federal University of Uberlândia, Uberlândia. MG, Brazil.

The purposes of this study were: 1 ) investigate whether different markers of inflammation (CRP and TNF- $\alpha$ ) are correlated to cardiorespiratory fitness in adolescents with obesity; 2 ) examine the association of these variables when adjusted by parameters of body composition. Were selected 57 individuals, 34 girls and 23 boys, with $16.4 \pm 1.56$ years and body mass index $36.0 \pm 4.3 \mathrm{~kg} / \mathrm{m}^{2}$. Anthropometric measurements (weight, height and abdominal circunference) and body composition (BMI, visceral fat, body fat) were assessment. Body composition was estimated by analyzer of tetrapolar bioelectrical impedance. Obesity was defined as BMI $>95$ th percentile of the curve proposed by the Center for Diseases Control. Plasma TNF- $\alpha$ was measured by a quantitative two-site high-sensitivity enzyme immunoassay and CRP was measured by high-sensitivity immunoturbidimetric assay. Graded maximal exercise testing was performed to obtain the maximum oxygen consumption $\left(\mathrm{VO}_{2 \max }\right)$ and velocity associated with the $\mathrm{VO}_{2 \max }\left(\mathrm{VVO}_{2 \text { max }}\right)$. Significant correlations of CRP with $\mathrm{VO}_{2 \max }$ and $\mathrm{vVO}_{2 \max }$ were found $(\mathrm{r}=-0.40$ and $\mathrm{r}=-0,36$, respectively). No correlations were observed between TNF- $\alpha$ and $\mathrm{VO}_{2 \max }$ e VVO ${ }_{2 \max }$ CRP was associated to the $\mathrm{VO}_{2 \max }$ and $\mathrm{VVO}_{2 \max }$ independently of measurements of body composition. The CRP was independently and inversely associated with direct measurement of $\mathrm{VO}_{2 \max }$ and the indirect variable of cardiorespiratory fitness $\mathrm{VVO}_{2 \max }$ in obese adolescents, even after adjustments in body composition, a potential confounding factor. No association was found between TNF- $\alpha$ and the parameters of cardiorespiratory fitness.

KEYWORDS: Ecytokines; Oxygen consumption; Treadmill test and exercise therapy.

\section{Introduction}

The increased prevalence of obesity in adolescence has become a public health problem ${ }^{1}$, because obesity in childhood and adolescence is strongly correlated with adult obesity, which reduces the quality of life of individuals and increases the economic costs of health care ${ }^{2}$.

Recent studies have demonstrated a systemic inflammation in obese children and adolescents, characterized by high level of pro-inflammatory cytokines and chemokines ${ }^{3,4}$. Another studies show a mediator role of systemic inflammation in the development of chronic diseases such as cardiovascular diseases and type 2 diabetes ${ }^{5-7}$. Therefore, adolescents with obesity are more exposed to possible comorbid conditions.

A high cardiorespiratory fitness is associated with a reduced systemic inflammation ${ }^{8}$. Previous studies have shown an inverse association between the C-reactive protein (CRP) and cardiorespiratory fitness ${ }^{9-11}$. However, research on the association between markers of inflammation and cardiorespiratory fitness were not performed with the obese adolescent, which would be important due to potential future prevention of comorbidities in this population.

In addition, the association between inflammatory markers and a practical parameter of prescription of training, which can be used in the 
field, as the velocity associated with maximum oxygen consumption $\left(\mathrm{vVO}_{2 \max }\right)$, has not yet been studied. The $\mathrm{vVO}_{2 \max }$ is defined as the speed which elicited the highest oxygen consumption, and was first examined by Cooper ${ }^{12}$, as an alternative method for predicting $\mathrm{VO}_{2 \max }$ in the effort to simplify the procedures of the tests and

\section{Methods}

One hundred and seventy-five participants were initially recruited for participation in this study which were medically screened, their pubertal stage was assessed, and their anthropometric measures were recorded (ie, height, weight and BMI). The endocrinologist completed a clinical interview including questions to determine eligibility based on inclusion criteria: being post-pubescent, according to the classification of TANNER and WHITEHOUSE ${ }^{13}$ and obese, BMI $>95$ th percentile of the curve proposed by the Center for Diseases Control (CDC); and exclusion criteria: identification of genetic, metabolic or endocrine diseases, and previous use of drugs. At the end of this screening were selected 57 individuals, 34 girls and 23 boys (TABLE 1). This study was approved by the Ethics Committee and Research in Human Beings of the Federal University of Uberlândia-Brazil and all the participants and their parents have signed a consent form.

Weight was measured by an electronic balance and height by a stadiometer. Body mass index (BMI) was calculated as kilograms per square meter. The abdominal circumference (AC) was assessed by perimeter of the abdomen at the height of the navel with a anthropometric tape (Sanny, $\mathrm{SN}-4010$, Brasil). Body composition was estimated by analyzer of tetrapolar bioelectrical impedance (Biodynamics, BIA310e, USA). Visceral fat (VF) was estimated by ultrasonography (Mindray, DC6 , China), defined as the distance between the internal surface of the abdominal rectus muscle and the anterior wall of the aorta ${ }^{14}$. All abdominal ultrasonographic (US) procedures and the measurements of visceral fat tissue were performed by the same physician. The intraexamination coefficient of variation for US was $2.6 \%$.

Blood samples were obtained by venipuncture after an overnight fast. Plasma TNF- $\alpha$ was measured reduce costs.

Thus, the purposes of this study were: 1) investigate whether different markers of inflammation (CRP and TNF- $\alpha$ ) are correlated to $\mathrm{vVO}_{2 \max }$ and $\mathrm{VO}_{2 \max }$ in adolescents with obesity; 2) examine the association of these variables when adjusted by parameters of body composition.

by a quantitative two-site high-sensitivity enzyme immunoassay (DRG Diagnostics, Germany), CRP by a polystyrene particle enhanced highsensitivity immunoturbidimetric assay (Aptec Diagnostics, Belgium)

Graded maximal exercise testing ( $2 \mathrm{~min}$ by stage, initial speed $-3 \mathrm{~km} \cdot \mathrm{h}^{-1}$, increase of $1 \mathrm{~km} \cdot \mathrm{h}^{-1}$ by stage and treadmill inclination fixed at 1\%) was performed on a motor-driven treadmill (Movement, RT 250pro, Brasil). A ergospirometer (Cosmed, FitMatePro, Italy) was used for analysis of the consumption of oxygen breathing by breathing. The maximum oxygen consumption $\left(\mathrm{VO}_{2 \max }\right)$ was defined as the highest 30-s average during exercise. The velocity associated with the $\mathrm{VO}_{2 \max }\left(\mathrm{vVO}_{2 \max }\right)$ was obtained by the following formula: $\mathrm{vVO}_{2 \max }\left(\mathrm{km} \cdot \mathrm{h}^{-1}\right)=\mathrm{v}+1.0 \mathrm{x}(\mathrm{t} / 120)$. Where $\mathrm{v}$ is the last velocity completed for 120 seconds; $\mathrm{t}$ the number of seconds the final not completed velocity was sustained; 1.0 is the value of the increase in velocity in $\mathrm{km} . \mathrm{h}-1$ from the last stage and 120 is the number of seconds in the stage ${ }^{15}$.

Initially, we tested the normality of all variables (Shapiro Wilk's test). CRP, TNF- $\alpha$, relative $\mathrm{VO}_{2 \max }$ and $\mathrm{vVO}_{2 \max }$ were logarithmically transformed $[\log (\mathrm{x}+1)]$ to reduce skewness. Descriptive statistics are given as mean (SD) (as well as range). The correlation between the parameters of cardiorespiratory fitness $\left(\mathrm{VO}_{2 \max }, \mathrm{vVO}_{2 \max }\right)$ and the markers of systemic inflammation (CPR and TNF- $\alpha$ ) was performed by Pearson's correlation coefficient. To assess whether inflammatory markers were independently associated with cardiorespiratory fitness after adjustment for potential confounders (body composition), was performed multivariable regression analyses. Predictive variables were included in models with a significance level of $p \leq 0,10$. Statistical significance was inferred at $\mathrm{p} \leq 0,05$. Statistical analyses were performed with Statistica version 7.0. 


\section{Results}

The participants characteristics are shown in TABLE 1. Significant correlations of CRP with $\mathrm{VO}_{2 \max }$ and $\mathrm{vVO}_{2 \max }$ are shown in FIGURE 1A and $\mathrm{B}$.

The relationship between the CRP and the $\mathrm{VO} 2$ max was reduced when adjusted for three variables of body composition, $r=-0,40$ for $\beta=-0,28$ (BMI), $\beta=-0,34$ (AC) and $\beta=-0,35$ (VF), as well as, two parameters have reduced the association between
CRP and vVO2max, $r=-0,36$ for $\beta=-0,29$ (AC) and $\beta=-0,31$ (VF), however these associations remained significant. No relationship was found between the CRP and the parameters of cardiorespiratory fitness when adjusted by BF (TABLE 2).

No correlations were observed between TNF- $\triangle$ and $\mathrm{VO} 2$ max e $\mathrm{vVO} 2$ max (figure $1 \mathrm{C}$ and $\mathrm{D}$ ), the association of these factors adjusted for body composition did not change the results (TABLE 2).

TABLE 1- Participants characteristics.

\begin{tabular}{|c|c|c|}
\hline & Mean (SD) & Range \\
\hline Age, years & $16.4(1.56)$ & $13.0-20.0$ \\
\hline \multicolumn{3}{|l|}{ Body Composition } \\
\hline Body mass index, $\mathrm{kg} / \mathrm{m} 2$ & $36.0(4.3)$ & $29.1-49.2$ \\
\hline Abdominal circumference, $\mathrm{cm}$ & $114.6(10.5)$ & $93.0-142.0$ \\
\hline Body fat, $\%$ & $33.5(5.5)$ & $20.0-44.4$ \\
\hline Visceral fat, $\mathrm{cm}$ & $3.7(1.1)$ & $1.5-6.5$ \\
\hline \multicolumn{3}{|l|}{ Cardiorespiratory Fitness } \\
\hline $\mathrm{VO} 2_{\max }, \mathrm{ml} \cdot \mathrm{kg}^{-1} \cdot \mathrm{min}^{-1}$ & $26.0(4.6)$ & $18.0-38.5$ \\
\hline $\mathrm{VO}_{2 \max }, \mathrm{L} \cdot \mathrm{min}^{-1}$ & $2.6(0.6)$ & $1.8-4.2$ \\
\hline Velocity associated with $\mathrm{VO}_{2 \mathrm{ma}} \mathrm{x}, \mathrm{km} \cdot \mathrm{h}^{-1}$ & $8.3(1.3)$ & $6.2-11.8$ \\
\hline \multicolumn{3}{|l|}{ Markers of Inflammation } \\
\hline $\mathrm{CRP}, \mathrm{mg} / \mathrm{dL}$ & $1.1(0.8)$ & $0.5-4.4$ \\
\hline TNF- $\alpha, p g / m L$ & $5.0(4.2)$ & $0.0-18.0$ \\
\hline
\end{tabular}

TABLE 2 - Association between markers of inflammation and cardiorespiratory fitness adjusted by parameters of body composition.

\begin{tabular}{lcccc}
\hline & \multicolumn{2}{c}{ CRP } & $\mathrm{c}$ TNF- $\alpha$ \\
\hline & $\beta$ & $\mathrm{p}$ & $\beta$ & $\mathrm{p}$ \\
$\mathrm{BMI} / \mathrm{vVO}_{2 \max }$ & $0,31^{\mathrm{a}} /-0,22$ & $0,03 / 0,11$ & $-0,27 / 0,08$ & $0,07 / 0,59$ \\
$\mathrm{BMI} / \mathrm{VO}_{2 \max }$ & $0,29^{\mathrm{a}} /-0,28^{\mathrm{a}}$ & $0,03 / 0,03$ & $-0,25 / 0,14$ & $0,08 / 0,34$ \\
$\mathrm{AC} / \mathrm{vVO}_{2 \max }$ & $0,26^{\mathrm{a}} /-0,29^{\mathrm{a}}$ & $0,05 / 0,03$ & $-0,04 / 0,19$ & $0,79 / 0,18$ \\
$\mathrm{AC} / \mathrm{VO}_{2 \max }$ & $0,24^{\mathrm{a}} /-0,34^{\mathrm{a}}$ & $0,05 / 0,01$ & $-0,03 / 0,23$ & $0,85 / 0,10$ \\
$\mathrm{BF} / \mathrm{vVO}_{2 \max }$ & $0,25 /-0,22$ & $0,09 / 0,13$ & $-0,12 / 0,13$ & $0,44 / 0,34$ \\
$\mathrm{BF} / \mathrm{VO}_{2 \max }$ & $0,23 /-0,27^{\mathrm{a}}$ & $0,10 / 0,03$ & $-0,10 / 0,19$ & $0,48 / 0,21$ \\
$\mathrm{VF} / \mathrm{vVO}_{2 \max }$ & $0,30^{\mathrm{a}} /-0,31^{\mathrm{a}}$ & $0,02 / 0,01$ & $0,06 / 0,21$ & $0,67 / 0,13$ \\
$\mathrm{VF} / \mathrm{VO}_{2 \max }$ & $0,28^{\mathrm{a}} /-0,35^{\mathrm{a}}$ & $0,03 / 0,01$ & $0,08 / 0,25$ & $0,57 / 0,06$ \\
\hline
\end{tabular}

Regression coefficient $\beta$ and $p$ values of multiple linear regression analysis; AC: abdominal circumference; BF: body fat; BMI: body mass index; CRP: C-reative protein; TNF- $\alpha$ : tumor necrose factor alpha; VF: visceral fat; $\mathrm{VO}_{2 \max }:$ maximum oxygen consumption; $\mathrm{VVO}_{2 \max }$ : velocity associated with $\mathrm{VO}_{2 \max }$. a: significant association. 
Scatter plots depicting correlation between log $(x+1)$ C-reactive protein (CRP), and $\log (x+1)$ tumor necrose factor

alpha (TNF- $\alpha$ ) with $\log (\mathrm{x}+1)$ maximal $\mathrm{O}_{2}$ consumption $\left(\mathrm{VO}_{2 \max }\right)$ and $\log (x+1)$ velocity associated with $\mathrm{VO}_{2 \max }$ $\left(\mathrm{VVO}_{2 \max }\right)$. Bold: significant association.
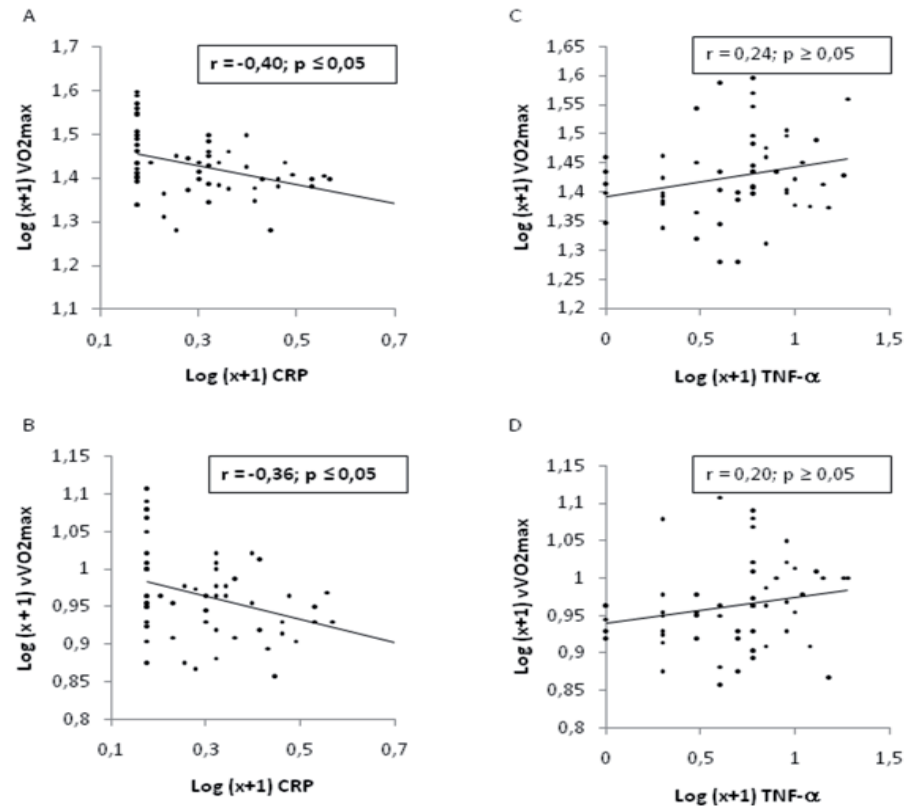

D

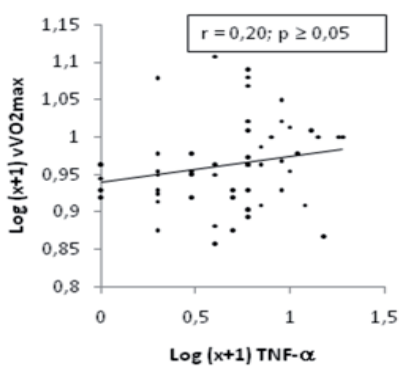

FIGURE 1- Correlations between markers of inflammation and cardiorespiratory fitness.

\section{Discussion}

The main finding of the present study was that, CRP was inversely related to $\mathrm{VO}_{2 \max }$ and $\mathrm{vVO}_{2 \max }$ (FIGURE $1 \mathrm{~A}$ and $\mathrm{B}$ ), even after adjustment for potential confounders such as BMI, AC and VF (TABLE 2), in adolescents with obesity. Although other studies have demonstrated the inverse correlation between inflammatory markers and cardiorespiratory fitness ${ }^{9-11}$, this is the first study to demonstrate: 1) this association in obese adolescents and 2) a significant correlation between the CRP and $\mathrm{vVO}_{2}$

It has been recommended for subjects with chronic diseases, including obese, exercise of moderate and vigorous intensities ${ }^{16-18 .}$ In this sense, the $\mathrm{vVO}_{2 \max }$ can be used as a reference for prescription of training, as shown in some studies ${ }^{19,20}$. It is a parameter which can be obtained in practice: it is viable and not requiring equipment of high cost and specialized personnel. Adding to this, the findings of this study, it becomes clear the usefulness of $\mathrm{vVO}_{2 \max }$ as a tool in the exercise evaluation for obese adolescents.

As $\mathrm{vVO}_{2 \max }$ and the $\mathrm{VO}^{2 \max }$ show similar correlations with inflammatory markers (FIGURE 1) and indicators of body composition (TABLE 3), we can infer that it can be reliably used for prescription of training in obese adolescents. The parameter most scientifically studied, $\mathrm{VO}_{2 \max }$, is not commonly available at training centers, gyms, parks and schools, and thus rarely used in the training prescription. In addition, the exercise based on $\mathrm{vVO}_{2 \max }$, reduces the empiricism and generalization, because suits the intensity to biological individuality of obese adolescents.

The levels of CRP were associated to the $\mathrm{VO}_{2 \max }$ and $\mathrm{vVO}_{2 \max }$ independently of measurements of body composition (TABLE 2). One study with 172 subjects aged 26-84 years also found a significant correlation $(\mathrm{r}=-0.40)$ between CRP and $\mathrm{VO}_{2 \max }$, which is in accordance with the data found in this study ${ }^{11}$. This finding is also consistent with the results of previous studies $^{10,21}$, however more studies are needed to clarify the reasons for this association.

The motives for the correlation between cardiorespiratory fitness and levels of CRP are not well elucidated. However, hepatic CRP production is stimulated by interlukin-6 (IL-6) and, to a lesser extent, by iterleukin-1 (IL-1) and TNF- $\alpha^{22}$. Individuals who are obese and/or hyperinsulinemic have increased adipocyte production of inflammatory markers, including IL-6 and TNF- $\alpha^{23-25}$. Several studies 
suggested a close relationship between cardiorespiratory fitness and inflammatory status ${ }^{26,27}$. Although we have not examined the concentrations of IL- 6 and IL-1, our study demonstrated a production of TNF- $\alpha$ in obese adolescents (TABLE 1), similarly to other studies $^{28}$. Whereas, the inverse correlation between the accumulation of body fat and cardiorespiratory fitness is well established, therefore, the relationship between, $\mathrm{CRP}, \mathrm{VO}_{2 \max }$ and $\mathrm{vVO}_{2 \max }$ should be mediated by the adipose tissue.

Association between the $\mathrm{VO}_{2 \max }, \mathrm{vVO}_{2 \max }$ and the TNF- $\alpha$ was not found (FIGURE $1 \mathrm{C}$ and D). The reason for increased circulating TNF- $\alpha$ levels observed in obese people is not thought to be associated with over-production in the adipose tissue. It is hypothesized that systemic effects of leptin or other adipokines may induce TNF- $\alpha$ secretion from macrophages and lymphocytes ${ }^{29}$. However, TNF- $\alpha$ is involved in the pathophysiology of obesity-associated insulin resistance and atherosclerosis ${ }^{30,31}$, therefore, the study of its association with the variables related to obesity still deserves attention.

Limitations of the present study include the relatively small sample size and cross-sectional design. Future studies are needed to identify which inflammatory pathway is associated with cardiorespiratory fitness and determine the pathophysiological mechanisms involved in this association.

In conclusion, the CRP was inversely associated with direct measurement of $\mathrm{VO}_{2 \max }$ and the indirect variable of cardiorespiratory fitness $\mathrm{vVO}_{2 \max }$, in obese adolescents, even after adjustments in body composition. No association was found between TNF- $\alpha$ and the parameters of cardiorespiratory fitness.

\section{Resumo}

Proteína $C$ reativa é inversamente e independentemente associada com o consumo máximo de oxigênio em adolescentes com obesidade

Os objetivos deste estudo foram: 1) investigar se diferentes marcadores da inflamação (PCR e TNF- $\alpha$ ) são correlacionados com a aptidão cardiorrespiratória em adolescentes com obesidade; 2) examinar a associação dessas variáveis quando ajustadas por parâmetros da composição corporal. Foram selecionados 57 indivíduos, 34 garotas e 23 garotos, com $16.4 \pm 1.56$ anos e índice de massa corporal de $36.0 \pm 4.3 \mathrm{~kg} / \mathrm{m} 2$. Mensurações antropométricas (massa corporal, estatura e circunferência abdominal) e de composição corporal (IMC, gordura visceral e massa gorda) foram realizadas. A composição corporal foi estimada por impedância biolétrica tetrapolar. A obesidade foi definida como IMC acima do percentil 95 da curva do CDC. 0 TNF- $\alpha$ plasmático foi mensurado por imunoensaio de alta sensibilidade e a PCR foi determinada por ensaio imunoturbidimétrico de alta sensibilidade. Teste incremental máximo foi realizado para obter o consumo máximo de oxigênio $\left(\mathrm{VO}_{2 \max }\right)$ e a velocidade associada ao $\mathrm{VO}_{2 \max }\left(\mathrm{VVO}_{2 \max }\right)$. Correlações significativas foram encontradas da PCR com o $\mathrm{VO}_{2 \max }$ e a vVO${ }_{2 \max }(r=-0.40$ e $r=-0,36$, respectivamente). Não foram observadas associações entre 0 $\mathrm{TNF}-\alpha, \mathrm{VO}_{2 \max }^{2 \max }$ e a $\mathrm{VOO}_{2 \max }{ }^{\max } \mathrm{A}$ PCR foi associada com o $\mathrm{VO}_{2 \max }$ e a $\mathrm{VVO}_{2 \max }$ independentemente dos parâmetros da composição corporal.

PalavRas-chave: Citocinas; Consumo de oxigênio; Teste incremental; Terapia e exercício.

\section{References}

1. Ebbeling CB, Pawlak DB, Ludwig DS. Childhood obesity: public-health crisis, common sense cure. Lancet 2002; 360:473-482.

2. Singh GK, Kogan MD, Van Dyck PC, Siahpush M. Racial/ethnic, socioeconomic, and behavioral determinants of childhood and adolescent obesity in the United States: analyzing independent and joint associations. Ann Epidemiol 2008;18(9):682-695.

3. Romeo J, Martinez-Gomez D, Diaz LE, Gómez-Martinez S, Marti A, Martin-Matillas M, et al. Changes in cardiometabolic risk factors, appetite-controlling hormones and cytokines after a treatment program in overweight 
adolescents: preliminary findings from the EVASYON study. Pediatric Diabetes 2011:12:372-380.

4. Breslin WL, Johnston CA, Strohacker K, Carpenter KC, Davidson TR, Moreno JP, et al. Obese mexican american children have elevated MCP-1, TNF-a, monocyte concentration, and dyslipidemia. Pediatrics 2012;129(5): e1180-1186.

5. Rana JS, Nieuwdorp M, Jukema JW, Kastelein JJ. Cardiovascular metabolic syndrome: an interplay of, obesity, inflammation, diabetes and coronary heart disease. Diabetes Obes Metab 2007;9(3):218-232.

6. Shoelson SE, Herrero L, Naaz A. Obesity, inflammation, and insulin resistance. Gastroenterology. 2007;132(6):21692180.

7. Rocha VZ, Libby P. Obesity, inflammation, and atherosclerosis. Nat Rev Cardiol 2009;6(6):399-409.

8. Thompson PD. Exercise and physical activity in the prevention and treatment of atherosclerotic cardiovascular disease. Arterioscler Thromb Vasc Biol 2003;23:1319-1321.

9. Rahimi K, Secknus MA, Adam M, Hayerizadeh BF, Fiedler M, Thiery J, et al. Correlation of exercise capacity with high-sensitive $\mathrm{C}$ reactive protein in patients with stable coronary artery disease. Am Heart J 2005;150:1282-1289.

10. Williams MJ, Milne BJ, Hancox RJ, Poulton R. C-reactive protein and cardiorespiratory fitness in young adults. Eur J Cardiovasc Prev Rehabil 2005;12: 216-220.

11. Kullo IJ, Khaleghi M, Hensrud DD. Markers of inflammation are inversely associated with VO2 max in asymptomatic men. J Appl Physiol 2007;102: 1374-1379.

12. Cooper KH. A mean of assessing maximal oxygen intake. JAMA 1968; 203: 201-4.

13. Tanner JM, Whitehouse RH. Clinical longitudinal standards for height, weight velocity and stages of puberty. Arch Dis Child 1976;51:170-179.

14. Ribeiro-Filho FF, Faria NA, Kohlmann O Jr, Ajzen S, Ribeiro AB, Zanella MT et al. Ultrasonography for the evaluation of visceral fat and cardiovascular risk. Hypertension 2001;38:713-717.

15. Kuipers H, Verstappen FT, Keizer HA, Geurten P, van Kranenburg G. Variability of aerobic performance in the laboratory and its physiological correlates. Int J Sports Med 1985; 6: 197-201.

16. Donnelly JE, Blair SN, Jakicic JM, Manore MM, Rankin JW, Smith BK. Appropriate Physical Activity Intervention Strategies for Weight Loss and Prevention of Weight Regain for Adults. American College of Sports Medicine position stand. Med Sc Sports Exerc 2009;41(2):459-471.

17. Sharman JE, Stowaser M. Australian association for exercise and sports science position statement on exercise and hypertension. J Sci Med Sport 2009;12(2):252-257.

18. World Health Organization: Global Recommendations on Physical Activity for Health: WHO 2010.

19. Rozenek R, Funato K, Kubo J, Hoshikawa M, Matsuo A. Physiological responses to interval training sessions at velocities associated with $\mathrm{VO}_{2 \max }$ J Strength Cond Res 2007;21(1):188-192.

20. Little JP, Safdar A, Wilkin GP, Tarnopolsky MA, Gibala MJ. A practical model of low-volume high-intensity interval training induces mitochondrial biogenesis in human skeletal muscle: potential mechanisms. J Physiol 2010;588(6):10111022.

21. Church TS, Barlow CE, Earnest CP, Kampert JB, Priest EL, Blair SN. Associations between cardiorespiratory fitness and C-reactive protein in men. Arterioscler Thromb Vasc Biol 2002;22:1869-1876.

22. Christos K, Paul DT. The effects of physical activity on serum C-Reactive protein and inflammatory markers. JACC 2005;45(10):1563-1569.

23. McLaughlin T, Abbasi F, Lamendola C, Liang L, Reaven G, Schaaf P, et al. Differentiation between obesity and insulin resistance in the association with C-reactive protein. Circulation 2002;106:2908 -2912.

24. Lavie CJ, Church TS, Milani RV, Earnest CP. Impact of physical activity, cardiorespiratory fitness, and exercise training on markers of inflammation. J Cardiopulm Rehabil Prev 2011;31(3):137-145.

25. Lira FS, Rosa JC, Dos Santos RV, Venancio DP, Carnier J, Sanches Pde L, et al. Visceral fat decreased by long-term interdisciplinary lifestyle therapy correlated positively with interleukin- 6 and tumor necrosis factor- $\alpha$ and negatively with adiponectin levels in obese adolescents. Metabolism 2011;60:359-365.

26. Mattusch F, Dufaux B, Heine O, Mertens I, Rost R. Reduction of the plasma concentration of C-reactive protein following nine months of endurance training. Int J Sports Med 2000; 21:21-24.

27. Petersen AMW, Pedersen BK. The anti-inflammatory effect of exercise. J Appl Physiol 2005 98: 1154-1162.

28. Gtowinska B, Urban M. Selected cytokines (Il-6, Il- 8, Il-10, MCP-1, TNF-alpha) in children and adolescents with atherosclerosis risk factors: obesity, hypertension, diabetes. Wiad Lek 2003; 56: 109-116.

29. Koistinen HA, Bastard JP, Dusserre E, Ebeling P, Zegari N, Andreelli F, et al. Subcutaneous adipose tissue expression of tumour necrosis factor-alpha is not associated with whole body insulin resistance in obese nondiabetic or in type-2 
diabetic subjects. Eur J Clin Invest 2000; 30: 302-310.

30. Yudkin JS. Inflammation, obesity, and the metabolic syndrome. Horm Metab Res 2007; 39(10):707-709.

31. Nieto-Vazquez I, Fernández-Veledo S, Krämer DK, Vila-Bedmar R, Garcia-Guerra L, Lorenzo M. Insulin resistance associated to obesity: the link TNF-alpha. Arch Physiol Biochem 2008;114(3):183-194.

\begin{tabular}{r|c} 
ADDRESs & \\
J oão Elias Dias Nunes & \\
Benjamin Constant Street, 1286 - Aparecida & Submitted: 12/22/2017 \\
38400-678 - Uberlândia - MG - Brazil & Revised: 02/02/2018 \\
E-mail: joaoeliasnunes@gmail.com; & Accepted: 02/07/2018 \\
joaoelias@faefi.ufu.br & \\
& \\
\hline
\end{tabular}

